2018 - Volume: 19 Number: 1

Page: $114-121$

DOI : $10.18038 /$ aubtda. 333956

Received: 10 August 2017 Revised: 06 December 2017 Accepted: 13 December 2017

\title{
XRD RAMAN AND Uv-vis SPECTROSCOPICAL ANALYSIS OF NANOSTRUCTURED CdS:Li FILMS
}

\author{
Tülay HURMA * \\ ${ }^{1}$ Department of Physics, Faculty of Science, Anadolu University, 26470, Eskişehir, Turkey
}

\begin{abstract}
CdS and CdS:Li films were produced by means of ultrasonic spray pyrolysis (USP) method by spraying on glass substrates heated up to $340 \pm 5{ }^{\circ} \mathrm{C}$. $\mathrm{LiCl}$ in three different rates was added into the preliminary solution while producing the $\mathrm{CdS}: \mathrm{Li}$ films. The effect of Li on the structural and optical characteristics of the CdS film was analyzed. XDR spectra showed that the crystallization degree decreases while lithium is $15 \%$ and increases when lithium rate increases. The crystallite sizes were calculated to be in the range of $60-85 \mathrm{~nm}$. SEM photographs showed that the contribution of Li changed surface appearances of films and their particle size. All films exhibited the Raman peaks centered 298 and $590 \mathrm{~cm}^{-1}$ and the peak profiles were almost symmetric. The optical band gap and Urbach energy values of these films were determined. The maximum transmittance was found to be almost $80 \%$ for the visible region. $\mathrm{LiCl}$ which was added to the preliminary solution changed the optical characteristics of CdS film.
\end{abstract}

Keywords: Li doped CdS film; XRD; Raman; Optical properties

\section{INTRODUCTION}

In the first quarter of the 21st century, perspective of people for energy resources changed. The effects such as extinction of fuel and other fossil fuels, environmental pollution and global warming made it necessary to search renewable energy resources. As a result of this search, solar cells were invented for wide use of solar power in daily life. Solar cell is a p-n junction which directly converts sunlight into solar power. Production of solar cells is partially easy and their field of use has been gradually expanding due to their characteristics as they are long-life devices if they are used properly; they do not require high temperatures for high efficiency, they have smaller size compared to the power they supply, they are not harmful on the environment and they can easily be moved. The basis of inorganic solar cells is the semiconductor thin film technology. Consequently, analyzing optical, electrical and structural characteristics of semiconductor thin films used mainly in the solar power systems and electronic and optoelectronic (light emitting diodes) circuit elements have become more important parallel to technological developments.

$\mathrm{CdS}$ as one of the II-VI group compounds is commonly used as the glazing material for (In, $\mathrm{Ga}) \mathrm{Se}_{2}$ and CdTe photovoltaic solar cells due to its band structure and $2.4 \mathrm{eV}$ optical band gap [1-5]. It is also applied in light emitting diodes (LED), photodetectors and thin film transistors and it is considered as n-type semiconductor due to its sulfur deficiency [6]. A variety of deposition techniques are used to deposit CdS films of desirable optical, electrical and structural properties; such as chemical bath deposition [7], thermal evaporation [8], screen printing [9], spray pyrolysis [10-12], etc. Among these techniques, ultrasonic spray pyrolysis (USP) method is a simple and economical one which does not require complex tools and vacuum, allows producing films with wider surface space and doped with different elements at the same time. The films obtained by this technique have polycrystalline structure. Study on the thin film technology for solar cells shows that based on the film applications, device quality $\mathrm{CdS}$ thin films can be produced by combining various dopant impurities while the film is being produced $[13,14]$. While, doping III, group elements of the periodic

*Corresponding Author: tulayhurma@gmail.com r 
table, such as Al, In and etc., cause changes on resistance and flaw density and doping alkali metals causes changes on optical characteristics of $\mathrm{CdS}$ material [15-17]. In the literature, the studies conducted on the effects of doping alkali metals on structural, optical, vibrational and superficial characteristics of $\mathrm{CdS}$ material are limited and the effects of doping Li on the structural and optical properties of CdS films produced by spray pyrolysis method have been reported, rarely. The doping materials and ratios are the parameters for determining the structural and optical properties of the $\mathrm{CdS}$ films produced by spray pyrolysis method. For this reason, $\mathrm{LiCl}$ in three different rates was used as the doping material and the effects of $\mathrm{Li}$ concentrations on structural and optical characteristics of CdS material were analyzed in this study.

\section{EXPERIMENTAL PROCEDURE}

$\mathrm{CdCl}_{2} \mathrm{H}_{2} \mathrm{O}(0.05 \mathrm{M}), \mathrm{H}_{2} \mathrm{NCSNH}_{2}(0.05 \mathrm{M}), \mathrm{LiCl}(0.01 \mathrm{M})$ aqueous solutions were used for producing $\mathrm{CdS}$ and CdS:Li films. The precursor solutions were produced by mixing these solutions in the rates mentioned in Table $1.100 \mathrm{ml}$ solution in total was previously sprayed on the glass substrates heated up to $340{ }^{\circ} \mathrm{C}$. By means of a Fluke 62 max infrared thermometer, substrate temperature was kept constant at $340 \pm 5{ }^{\circ} \mathrm{C}$. The distance of the ultrasonic spray head to the substrate was almost $30 \mathrm{~cm}$. The flow rate of solution was adjusted to be $5 \mathrm{ml} \mathrm{min}^{-1}$ and $0.2 \mathrm{~kg} \mathrm{~cm}^{-2}$, respectively during spraying under control of flow meter and carrier gas pressure. Carrier gas used in this process was nitrogen. XRD measurements were conducted for determining the produced crystallization levels and phases. These measurements were conducted by using a CuK $\alpha$ ray with $\lambda=1,541 \AA$ wavelength and BRUKER D8 Advance X-ray diffractometer. The XRD pattern was scanned in $2 \theta$ range of $20^{\circ}-70^{\circ}$. The films were mounted on rotating sample holders (at $15 \mathrm{rpm}$ ). Surface images were obtained by using a ZEISS Ultra plus model scanning electron microscope (FESEM)). Raman measurements were conducted at 50-3500 $\mathrm{cm}^{-1}$ range by Bruker Senterra Dispersive Raman system (with He-Ne laser) at a wavelength of $632.8 \mathrm{~nm}$. Optical absorption and reflectance spectrum of the films were measured in 200-900 nm wavelength range by using Shimadzu $2450 \mathrm{UV}$ model spectrometer.

Table 1. Precursor solutions of the CdS and CdS:Li films

\begin{tabular}{cccc}
\hline Film & $\mathrm{CdCl}_{2} \mathrm{H}_{2} \mathrm{O}(\mathrm{ml})$ & $\mathrm{LiCl}(\mathrm{ml})$ & $\mathrm{H}_{2} \mathrm{NCSNH}_{2}(\mathrm{ml})$ \\
\hline CdS & 50 & --- & 50 \\
CdS:Li (15\%) & 35 & 15 & 50 \\
CdS:Li (25\%) & 25 & 25 & 50 \\
CdS:Li (35\%) & 15 & 35 & 50 \\
\hline
\end{tabular}

\section{RESULTS AND DISCUSSIONS}

\subsection{X-ray Diffraction Pattern of the Film}

The crystallinity and the preferred crystal orientation of the films were analyzed by the XRD method. Figure 1 shows the diffraction patterns of pure the CdS and the Li doped CdS films. X-ray diffraction patterns of the films were measured in $20^{\circ} \geq 2 \theta \geq 70^{\circ}$ range. It was observed from the XRD diffraction patterns that the films had polycrystalline structure. Crystallization degree decreased while lithium was $15 \%$ and increased when lithium rate increased. Orientations of crystal planes were in hexagonal form and the CdS structure and at (100), (002), (101), (102) (110), (103) and (112) directions (JCPDS 041-1049). Preferential orientation of the CdS, which was (101), changed for $\mathrm{Li} 25 \%$ and $\mathrm{Li} 35 \%$ film as (002). Changes occurred in the intensity of the main peaks were scribed to the rotation of some crystalline grains during the preparation processes. The same phenomena have been observed for $\mathrm{Li}$ doped CdS thin films, produced by sol-gel spin-coating technique reported by [18]. The peak for $\mathrm{Cd}$ 
was observed in addition to the lithium doped diffraction patterns of the films (JCPDS: 03-065-3363). From these diffraction patterns, the crystallite sizes were calculated by means of Scherrer formula [19] and the CdS for $\mathrm{Li} \mathrm{15 \% ,} \mathrm{Li} 25 \%$ and $\mathrm{Li} 35 \%$ films and found respectively as $76 \mathrm{~nm}, 60 \mathrm{~nm}, 50$ $\mathrm{nm}$ and $65 \mathrm{~nm}$.

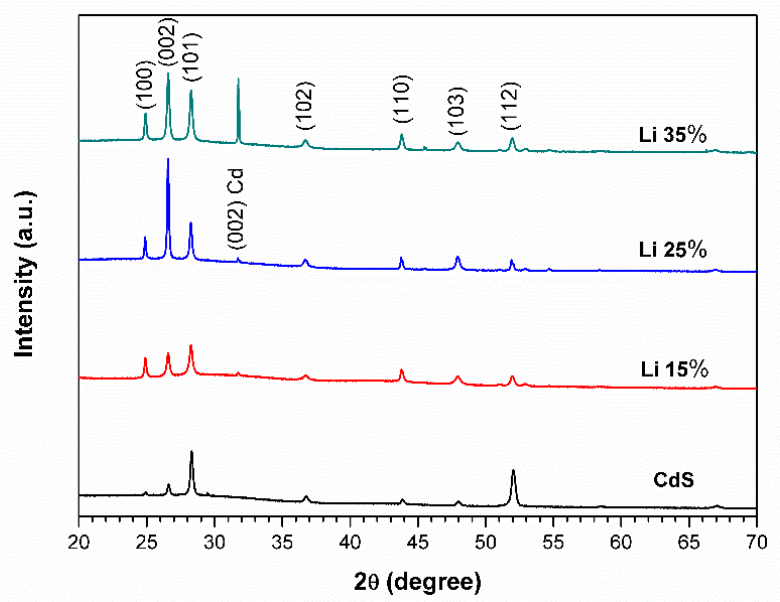

Figure 1. XRD spectra of the CdS and CdS:Li nanostructured films

Surface images were taken by $100000 \times$ magnification (Figure 2). When, the surface images of the films were analyzed, it was observed that the Li doping caused changes on surface appearances and particle sizes. The particle sizes on the surfaces of $\mathrm{Li} 15 \%$ and $\mathrm{Li} 25 \%$ films were not very distinct. It was evaluated that the spandrel particles were dominant on the surface of the CdS film and the spandrel particles became round when preferential orientation began changing as a result of $\mathrm{Li}$ doping. Particle sizes are consistent with the crystallite sizes found from the XRD results. An idea about the particle size is obtained from the SEM photograph and it helps to determine the range of particle size.
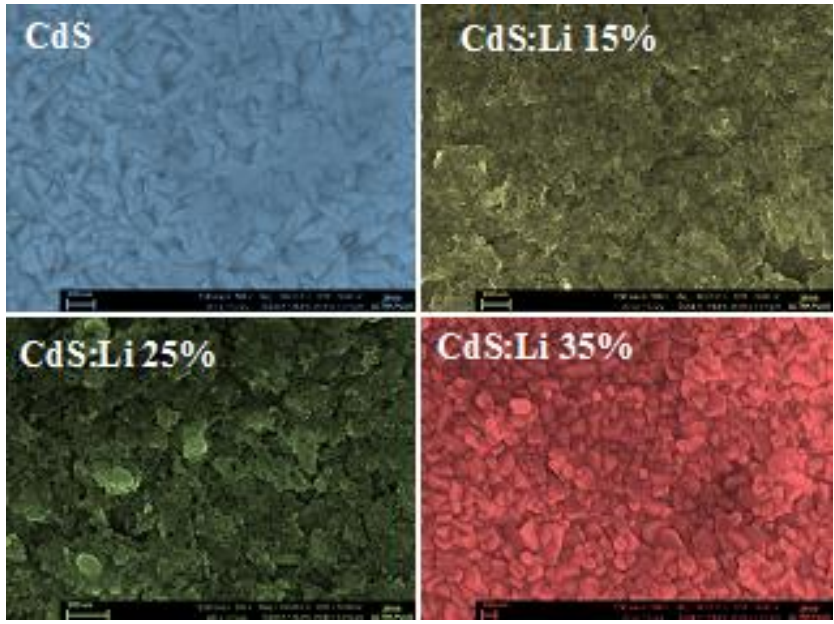

Figure 2. SEM images of the CdS and CdS:Li nanostructured films

\subsection{Raman Spectroscopy}

Theoretical foundations of Raman spectroscopy has been laid in 1930s, however because of the equipment needed for capturing the weak Raman signal and the problems related with laser technology, the studies on extending this technique have been continued up to now. Raman scattering 
can be used for characterizing a structure in crystal form [20]. Figure 3 shows the room temperature the Raman spectra of the films. Two distinct active Raman modes were observed on the spectrums.

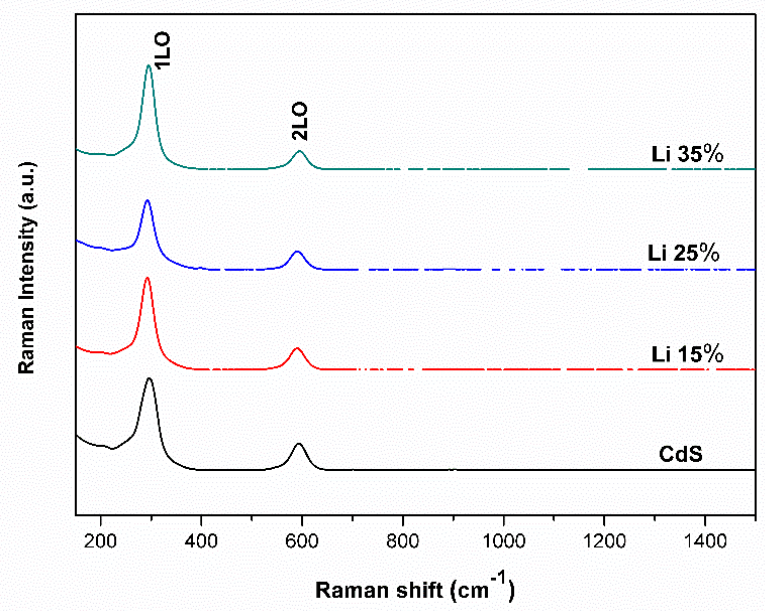

Figure 3. Raman spectra of the CdS and CdS:Li nanostructured films

The peaks observed around $298 \mathrm{~cm}^{-1}$ and $590 \mathrm{~cm}^{-1}$ belong to bulk CdS vibration mode [5].There are changes in strengths of peaks. Raman strengths are mostly proportional to the concentration of active particles. Asymmetric formation of peaks makes you think there are defects in the structure. As it is seen from Figure 4, it is observed that the bulk CdS lattice vibration mode which had been seen at 298 $\mathrm{cm}^{-1}$ shifted to a lower part. Shifts increase as the particle size decreases. Peaks may shift to lower values for thin films by diminishing particle size and the effect of phonon formation [21]. The particle sizes of films can be compared by matching individual positions of peaks of CdS films.

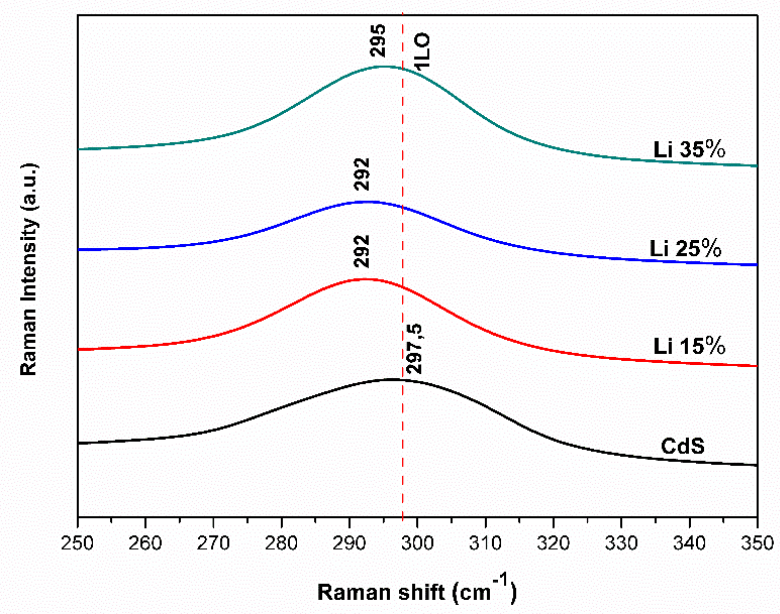

Figure 4. Raman spectrum shift of the CdS and CdS:Li nanostructured films

\subsection{UV-Visible Studies}

Traveling of the light reflecting and penetrating through the thin film is different than its traveling in normal medium. Reflection and diffraction of light through a film are based on magnitudes such as film thickness, refraction index and extinction coefficient. In Figure 5, the transmittance spectra of the films against wavelengths are seen. As it is seen from the figure, transmittance value in the visible region $(\lambda=500 \mathrm{~nm})$ increased from $55 \%$ maximum and $87 \%$ in the near infrared region $(\lambda=900 \mathrm{~nm})$. The highest transmittance value belongs to CdS: Li 15\% film. Also for high-Li-containing films, 
transmittance values decreased and reflectance values increased in the visible region. This might be due to the influence of various factors such as structural parameters, carrier concentrations and defects.

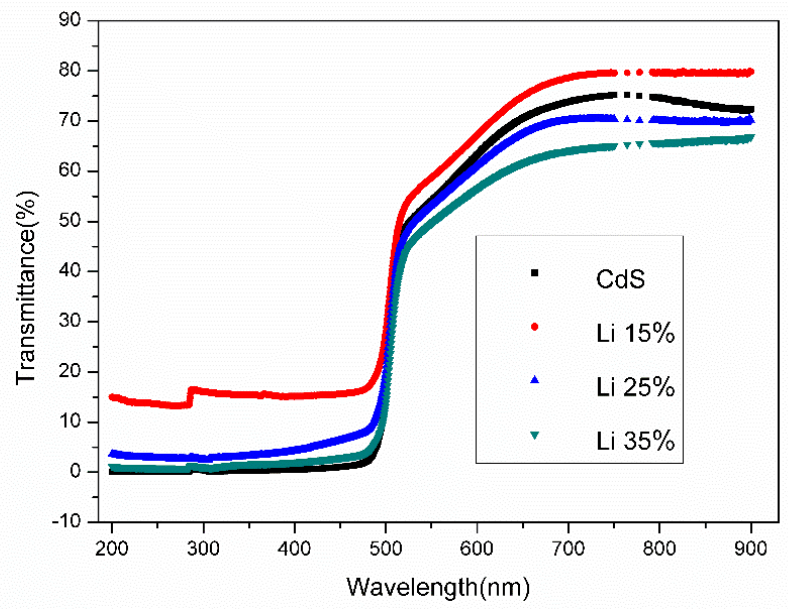

Figure 5. The transmittance spectra of CdS and CdS:Li nanostructured films

The reflectance spectra of films are seen in Figure 6. Increasing reflectance values were observed as the doped Li amount increased. One of the optic factors, the extinction coefficient $(\mathrm{k})$ is extremely important for determining the optical characteristics of the materials to be used in solar cells. Extinction coefficient of a material is based on its absorption values. The extinction coefficient values were determined by means of the (1) expression [22].

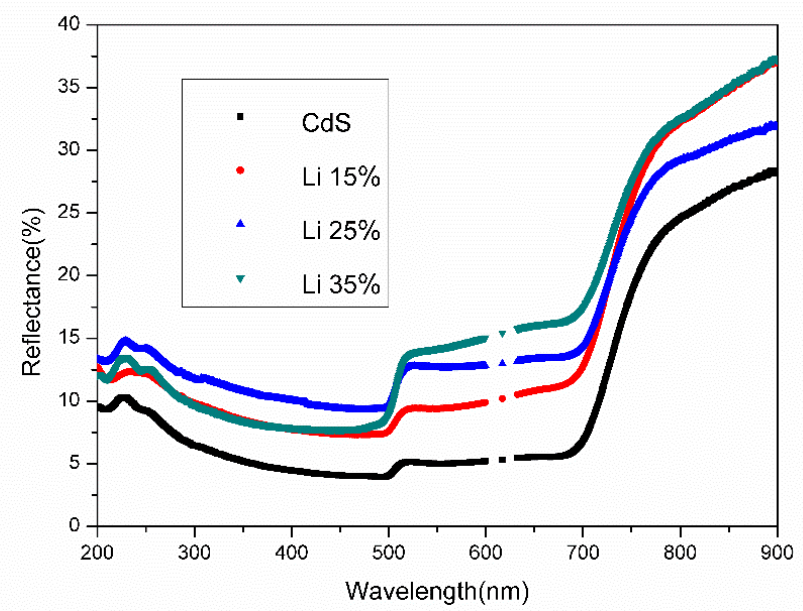

Figure 6. The reflectance spectra of CdS and CdS:Li nanostructured films

$$
k=\frac{\alpha \lambda}{4 \pi}
$$

The change of extinction coefficients of films based on wavelength can be seen in Figure 7. In the visible region $(\lambda=475 \mathrm{~nm})$, extinction coefficients of films are in between 0,03 and 0,07 . Minimum value belongs to CdS: $\mathrm{Li} 15 \%$ film and in relation to this, the transmittance value of the CdS: Li15\% film in this region is the highest. Several studies show that optical absorption of a semiconductor does not increase smoothly and very fast in the optical band gap. But in many materials, the optical 
absorption spectrum starts near the limit that it should. The cause of this is band tails. Band tails on the edge of bands can be found in all crystal or amorphous structures. Static stresses and defects are the factors that play an effective and leading role in the formation of these tails. Furthermore, temperature change has an impact through its dynamic effect. If, lower dynamic effects are ignored, Urbach rule under static effect is;

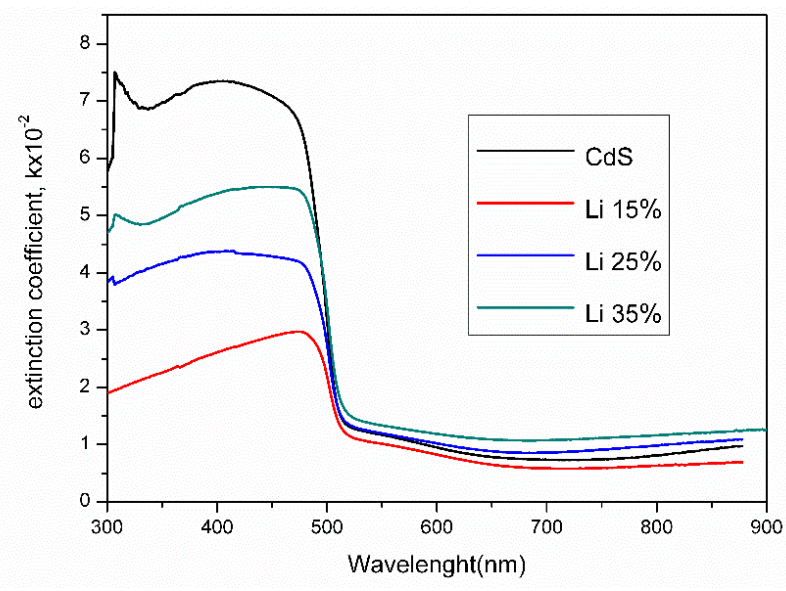

Figure 7. Variation of extinction coefficient of the films with wavelength

$$
\alpha=\alpha_{o} \exp \left(\frac{E}{E_{U}}\right)
$$

given by the equation above [23] and Urbach parameter $\mathrm{E}_{\mathrm{U}}$;

$$
E_{U}=\left(\frac{d(\ln \alpha)}{d(h v)}\right)^{-1}
$$

can be found by the equation above. For calculating Urbach parameters, the $\ln (\alpha) \sim \mathrm{h} v$ graphic was drawn as seen from Figure 8.

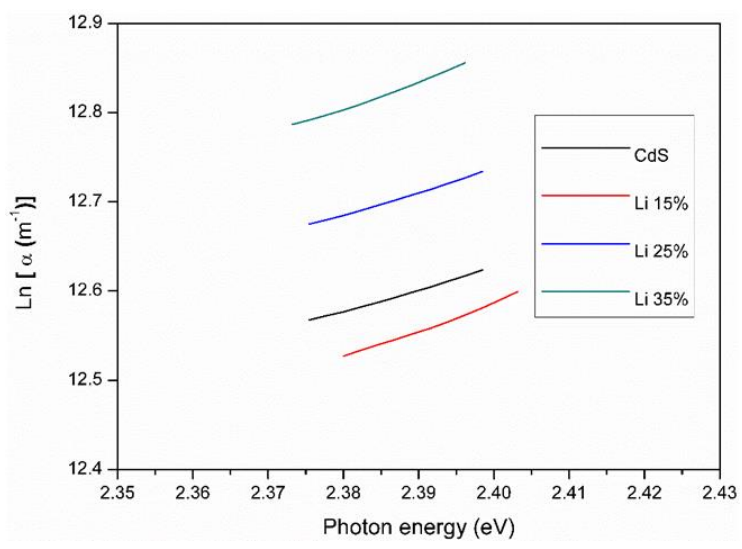

Figure 8. The Urbach plots of the CdS and CdS:Li films

Urbach parameters calculated by means of the Equation (3) are given in Table 2. Band tails, in any semiconductor, crystalline or amorphous structure narrow the optical band gap and cause an increase in the absorption spectrum. As shown in Table 2, the optical band gap (Eg) also tends to decrease with 
Li doping due to the increase in its carrier concentration [24,25]. A shift higher wavelength side in the absorption edge towards lower band gap is noticed in all Li doped CdS thin films [18].

Table 2. $\mathrm{E}_{\mathrm{g}}$ and $\mathrm{E}_{\mathrm{U}}$ values of the CdS and CdS:Li films

\begin{tabular}{lcccc}
\hline & CdS & CdS:Li (15\%) & CdS:Li (25\%) & CdS:Li (35\%) \\
\hline $\mathrm{E}_{\mathbf{g}}(\mathbf{e V})$ & 2.415 & 2.413 & 2.405 & 2.395 \\
$\mathrm{Eu}(\mathbf{m e V})$ & 596 & 546 & 769 & 911 \\
\hline
\end{tabular}

\section{CONCLUSIONS}

Polycrystalline $\mathrm{CdS}$ films were established on glass substrates by producing $\mathrm{CdS}$ and $\mathrm{Li}$ in three different rates. XRD and Raman spectroscopy practices were used for determining the crystallization quality and phase contents of these films which were produced by means of Spray Pyrolysis method. XRD results show that lithium which was added into the spray solution in various rates, influenced the crystallization rates of films and preferential orientation, which had been (101) for the CdS film, was changed as (002) for Li 25 and Li 35 films. Two apparent active Raman modes of bulk CdS were observed around $298 \mathrm{~cm}^{-1}$ and $590 \mathrm{~cm}^{-1}$. Lattice vibration mode observed in Li containing films around $300 \mathrm{~cm}^{-1}$ shifted to a lower part. Optical measurements show that the highest transmittance value belongs to $\mathrm{CdS}$ : Li $15 \%$ film. Increasing reflectance values of films and changing Urbach energy values were observed, as a result of increasing Li rate in the preliminary solution.

\section{ACKNOWLEDGEMENT}

Hereby, we thank Mrs. Özge BAĞLAYAN for the Raman spectroscopy, Mrs. Seval AKSOY for SEM, Mrs. Büşra AVCı for UV-vis and Mrs. Pınar Bilgiç ÖZDEN for XRD measurements.

\section{REFERENCES}

[1] Durose K, Edwards PR, Halliday DP. Materials aspects of CdTe/CdS solar cells, J Cryst Growth 1999; 197: 733-742.

[2] Voss C, Subramanian S, Chang CH. Cadmium sulfide thin-film transistors fabricated by lowtemperature chemical-bath deposition. J Appl Phys 2004; 96: 5819-5823.

[3] Mereu B, Sarau G, Pentia E, Draghici V, Lisca M, Botila T, Pintilie L. Field-effect transistor based on nanometric thin CdS films. Mater Sci Eng 2004; B109: 260-263.

[4] Seon JB, Lee S, Kim JM, Jeong HD. Spin-coated CdS thin films for n-channel thin film transistors. Chem Mater 2009: 21: 604-611.

[5] Arreola-Jardón G, González LA, García-Cerda LA, Gnade B, Quevedo-López MA, Ramírez-Bon R. Ammonia-free chemically deposited $\mathrm{CdS}$ films as active layers in thin film transistors. Thin Solid Films 2010; 519: 517-520.

[6] Rmili A, Ouachtari F, Bouaoud A, Louardi A, Chtouki T, Elidrissi B. Erguig H. Structural, optical and electrical properties of Ni-doped CdS thin films prepared by spray pyrolysis. Journal of Alloys and Compounds 2013; 557: 53-59.

[7] Yücel E, Şahin O. Effect of $\mathrm{pH}$ on the structural, optical and nanomechanical properties of CdS thin films grown b ychemical bath deposition. Ceramics International 2016; 42: 6399-6407. 
Hurma / Anadolu Univ. J. of Sci. and Technology A-Appl. Sci. and Eng. 19 (1)-2018

[8] Sahay PP, Nath RK, Tewari S. Optical properties of thermally evaporated CdS thin films. Cryst Res Technol 2007; 42 (3) 275-280.

[9] Patidar D, Sharma R, Jain N, Sharma TP, Saxena NS. Optical properties of CdS sintered film. Bull Mater Sci 2006; 29 (1): 21-24.

[10] Ashour A. Physical properties of spray pyrolysed CdS thin films. Turk J Phys 2003; 27: 551-558.

[11] Bilgin V, Kose S, Atay F, Akyuz I. The effect of substrate temperature on the structural and some physical properties of ultrasonically sprayed CdS films, Mater Chem Phys 2005; 94: 103-108.

[12] Pence S, Varner E, Clayton W. Substrate temperature effects on the electrical properties of CdS films prepared by chemical spray pyrolysis. Mater Lett 1995; 23: 13-16.

[13] Nakayana N. Ceramic CdS solar cell, Jpn. J Appl Phys 1969; 8: 450-462.

[14] Shikalgar AG, Pawar SH. The cadmium sulphide-lithium thin films were prepared by the chemical bath deposition, Thin Solid Films 1979; 61: 313-320.

[15] Khallaf H, Chai G, Lupan O, Chow L, Park S, Schulte A. Investigation of aluminium and indium in situ doping of chemical bath deposited CdS thin films. J Phys D Appl Phys 2008; 41: 185304185313.

[16] Muthusamy M, Muthukumaran S, Ashokkumar M. Composition dependent optical, structural and photoluminescence behaviour of $\mathrm{CdS}$ : $\mathrm{Al}$ thin films by chemical bath deposition method Ceramics International 2014; 40: 10657-10666.

[17] Naumov AV, Bolgova TG, Semenov VN, Maiorova TL, Klyuev VG. Luminescence and photoconductivity of alkali-metal-doped cadmium sulfide films. Inorg Mater 2006; 42: 463-469.

[18] FS Hashim, BK, Kahdum, Effect of Li doping on the structural and some optical studies of CdS thin films fabricated by sol-gel technique. 2016; 4: 155-164.

[19] BD Cullity, SR. Stock, Elements of X-ray Diffraction, Prentice Hall, Upper Saddl River. NJ, 2001.

[20] Nalwa HS. Nanostructured Materials and Nanotechnology, Academic Press, San Diego, 2002.

[21] Leite RCC, Porto SPS. Enhancement of Raman Cross Section in CdS due to Resonant Absorption, Phys Rev Lett 1966; 17: 10-12.

[22] Caglar M, Ilican S, Caglar Y. Influence of dopant concentration on the optical properties of $\mathrm{ZnO}$ : In films by sol-gel method. Thin Solid Films 2009; 517: 5023-5028

[23] Urbach F. The long-wavelength edge of photographic sensitivity and of the electronic absorption of solids. Phys Rev 1953; 92: 1324-1326.

[24] Caglar Y, Caglar M, Ilican S. Microstructural, optical and electrical studies on sol gel derived $\mathrm{ZnO}$ and $\mathrm{ZnO}$ : Al films. Current Applied Physics vol. 12, 2012, 963-968.

[25] Ikhmayies SJ, Ahmad-Bitar RN. The influence of the substrate temperature on the photovoltaic properties of spray-deposited CdS:In thin films. App Surf Sci 2010; 256: 3541-3545. 